\title{
Ecological Momentary Assessment of Bipolar Disorder Symptoms and Partner Affect: Longitudinal Pilot Study
}

Mor Yerushalmi ${ }^{1}$; Andrew Sixsmith ${ }^{2}$, PhD; Ariel Pollock Star ${ }^{3}$, MA; David B King ${ }^{4}, \mathrm{PhD}$; Norm O'Rourke ${ }^{5}$, PhD

${ }^{1}$ Department of Psychology, Ben-Gurion University of the Negev, Be'er Sheva, Israel

${ }^{2}$ Science and Technology for Aging Research (STAR) Institute, Simon Fraser University, Vancouver, BC, Canada

${ }^{3}$ Department of Public Health, Ben-Gurion University of the Negev, Be'er Sheva, Israel

${ }^{4}$ Department of Psychology, University of British Columbia, Vancouver, BC, Canada

${ }^{5}$ Department of Public Health and Multidisciplinary Center for Research on Aging, Ben-Gurion University of the Negev, Be'er Sheva, Israel

\section{Corresponding Author:}

Norm O'Rourke, $\mathrm{PhD}$

Department of Public Health and Multidisciplinary Center for Research on Aging

Ben-Gurion University of the Negev

P O Box 653

Be'er Sheva, 8410501

Israel

Phone: 972549901808

Fax: 97286477635

Email: ORourke@bgu.ac.il

\section{Abstract}

Background: The World Health Organization ranks bipolar disorder (BD) as the 7th leading cause of disability. Although the effects on those with BD are well described, less is reported on the impact of BD on cohabiting partners or any interactions between the two; this requires in vivo data collection measured each day over several months.

Objective: We set out to demonstrate the utility of ecological momentary assessment with BD couples measured using yoked smartphone apps. When randomly prompted over time, we assumed distinct patterns of association would emerge between BD symptoms (both depression and hypo/mania) and partner mood (positive and negative affect).

Methods: For this pilot study, we recruited an international sample of young and older adults with BD and their cohabiting partners where available. Both participants and partners downloaded separate apps onto their respective smartphones. Within self-specified "windows of general availability," participants with BD were randomly prompted to briefly report symptoms of depression and hypo/mania (ie, $\mathrm{BDS}_{\mathrm{x}}$ ), positive and negative mood (ie, POMS-15; partners), and any important events of the day (both). The partner app was yoked to the participant app so that the former was prompted roughly 30 minutes after the participant with BD or the next morning if outside the partner's specified availability.

Results: Four couples provided 312 matched BD symptom and partner mood responses over an average of 123 days (range 65-221 days). Both were GPS- and time-stamped (mean 3:11 hrs between questionnaires, SD 4:51 hrs). Total depression had a small but significant association with positive $(\mathrm{r}=-.14 ; P=.02)$ and negative partner affect $(\mathrm{r}=.15 ; P=.01]$. Yet total hypo/mania appeared to have no association with positive partner affect ( $\mathrm{r}=-.01 ; P=.87)$; instead, negative partner affect was significantly correlated with total hypo/mania $(\mathrm{r}=.26 ; P=.01)$. However, when we look specifically at $\mathrm{BD}$ factors, we see that negative partner affect is associated only with affrontive symptoms of hypo/mania $(\mathrm{r}=.38 ; P=.01)$; elation or loss of insight appears unrelated to either positive $(\mathrm{r}=.10 ; P=.09)$ or negative partner affect $(\mathrm{r}=.02 ; P=.71)$. Yet affrontive symptoms of hypo/mania were significantly correlated with negative affect, but only when couples were together $(\mathrm{r}=.41 ; P=.01)$, not when apart $(\mathrm{r}=.22 ; P=.12)$. That is, these angry interpersonal symptoms of hypo/mania appear to be experienced most negatively by spouses when couples are together.

Conclusions: These initial findings demonstrate the utility of in vivo ambulatory data collection in longitudinal mental health research. Preliminary analyses suggest different BD symptoms are associated with negative and positive partner mood. These negative effects appear greater for hypo/mania than depressive symptoms, but proximity to the person with BD is important.

(JMIR Form Res 2021;5(9):e30472) doi: 10.2196/30472 


\section{KEYWORDS}

bipolar disorder; couples; dyadic analyses; ecological momentary assessment; EMA; bipolar disorder; partner; relationships; mHealth; mobile apps; mental health; depression; BPD; mood

\section{Introduction}

\section{Background}

One clinical feature of bipolar disorder (BD) is variable awareness of symptoms, their severity, and impact on others; this appears especially true when manic [1]. Fortunately, smartphones today enable active and passive measurement of mood and behavior for those with mental health conditions [2-4], including BD [5-7]. Both prompted data collection [8], and embedded sensors [9] enable smartphones to capture, synthesize, and share information from those with BD and their carers (eg, spouses) [10].

For the bipolar affective disorders and older adults (BADAS) study, we randomly prompted and measured BD symptoms in the moment [11]. For this pilot study, a subset of BADAS participants with cohabiting partners downloaded the carers app onto their smartphone. We set out to demonstrate the viability of dyadic ecological momentary assessment (EMA) and to compare BD symptoms (both depression and hypo/mania) and partner mood (positive and negative affect) over time.

For this pilot study, we had two specific aims. First, to demonstrate the utility of in vivo, ambulatory assessment with BD couples (ie, yoked smartphone apps). Essentially, would persons with $\mathrm{BD}$ and their cohabiting carers regularly provide subjective information when randomly prompted by their respective smartphones? Assuming that ambulatory data collection proves effective, are BD symptoms and partner mood correlated when measured each day over several months? And if so, in which directions (eg, depression correlated with negative partner affect)?

Data collection via smartphone app allowed us to determine who responded first each day (i.e., participant then his or her partner; or partner then participant), the interval between their respective responses, and whether they were together or apart (ie, shared vs distinct GPS coordinates).

\section{BD Symptom Measurement}

With few exceptions, BD symptom scales rely on both self-report and memory (eg, recall over the past week or month) [12]. Yet research indicates that retrospective responses are affected by recall (eg, forgetting) and various response biases [13]. For instance, end-of-day retrospective reports capture just $26 \%$ to $37 \%$ variability in mood compared to in-the-moment responses obtained earlier that day [14]. Moreover, recall accuracy declines at times of increased life stress.

This has fostered observational and objective measurement, while euthymic and symptomatic $[15,16]$ and where people with BD work and live $[17,18]$. Initial research suggests that the use of smartphones can foster self-insight and help forestall BD mood episodes when patients are medication adherent [19]. This is possible because smartphones are ubiquitous today and can measure, store, and transmit data in real-time, along with location and biometric data [20-22]. This allows us to identify person-specific factors associated with the onset and maintenance of BD mood episodes [23], including the ability to sustain supportive relationships, which are important to wellness with BD over time [24].

\section{BD Carer Well-Being}

BD affects not only those diagnosed but also their family, friends, coworkers, and neighbors $[25,26]$. The negative impact of $\mathrm{BD}$ on carers includes mood episodes (depression and hypo/mania) [27], financial problems [28], and reduced social and functional well-being [29]. As a result, quality of life for BD carers can be severely impacted [30]. Compared to those caring for those with major depression, BD carers report greater burden and role strain [31].

According to Reinares et al [32], carer burden is greatest when those with BD are agitated, irritated, and depressed. Yet suicidal ideation causes carers greatest distress [33]. One challenge for BD carers is loss of control as BD mood episodes are generally unannounced, patients can present with depression, hypo/mania, or both [34], and recovery between episodes is often incomplete [35-37].

Though research examining the impact of BD on friends and family has grown in recent decades [38], all studies to date are based on retrospective questionnaire responses [31,39] or limited by very small sample sizes due, in part, to the low BD prevalence [40]. Social media recruitment for the BADAS study enabled the enrollment of an international sample of young and older adults with BD and their cohabiting spouses or partners when available.

\section{Methods}

\section{Study App Development}

The BADAS study app and data collection platform were developed, tested, and refined over 2 years, including iterative pilot testing in the field to ensure the app functioned as intended and data are reported as recorded (eg, GPS coordinates corroborated by self-reported location). Pilot testing occurred across multiple locations and time zones [8].

\section{BADAS Study Recruitment}

We first recruited 50 adults with BD living in Canada, the United States, the United Kingdom, South Africa, and Australia. Participants were recruited using microtargeted social media advertising drawn from a global population of 6.2 million English-speaking, adult Facebook users with 'bipolar disorder interests' (eg, members of online BD support networks). As described elsewhere in more detail [41], machine-generated algorithms calculated by social media platforms are unique not so much for their sensitivity but specificity (ie, exclusion of those who do not have BD). Thus, persons recruited via Facebook do not represent the population, but we can be 
confident these are persons with BD because only persons with $\mathrm{BD}$ received the advertisements.

After clicking the ad, prospective participants were directed to a website describing the study; if eligible and interested, they were asked to provide their names and contact information. During screening interviews (telephone, Zoom, or Skype), prospective participants confirmed their BD diagnosis and provided emergency contact information (eg, psychiatrist). This was prudent, as bipolar disorder has the highest rate of suicide of all mental health conditions [42]. Ethics approval for this study was provided by Simon Fraser University, Burnaby, British Columbia, Canada.

\section{Partners of Persons with BD}

Participants were also asked if they currently lived with a spouse or partner and to provide their partner's email address. Only with the participant's permission did we send email requests to their respective partners, inviting their participation. Both were assured that no information would be shared between them. Despite this, most BADAS participants requested that we not invite their spouses or partners to take part. Only 3 women and 1 man agreed and downloaded the partner app onto their smartphones (eg, App Store). No partners were lost to attrition.

Figure 1. Four-factor model of bipolar disorder symptoms.
We purposefully recruited partners without mental health diagnoses; one couple, in which both partners had BD, was excluded. This allowed us to examine associations between normal affect and BD symptoms (ie, pathology).

\section{Instruments}

The bipolar disorder symptom scale $\left(\mathrm{BDS}_{\mathrm{x}}\right)$ [43] was developed for brief, ambulatory assessment of depression and hypo/mania. Respondents indicate the degree to which each of 20-mood adjectives corresponds to how they feel right now, at that moment. Research suggests a four-factor structure: two depression (cognitive and somatic) and two hypo/mania factors (elation or loss of insight and affrontive symptoms). The two depression and two hypo/mania factors are correlated, and affrontive symptoms of hypo/mania (eg, furious, disgusted, argumentative) are positively correlated with both depression factors suggesting pathways for mixed symptom presentation [44]. The construct validity of this four-factor model of symptomology was demonstrated across BD subtypes [45] and relative to quality of life with BD [46] (Figure 1).

The $\mathrm{BDS}_{\mathrm{x}}$ was developed for ecological momentary sampling of BD symptoms via smartphone app $[43,44]$ but has also been validated for use online $[45,46]$ and as a printed-page screening measure with BD outpatients $[47,48]$. In this study, $\alpha=.88$ for depressive symptoms and $\alpha=.71$ for the hypo/mania subscale.

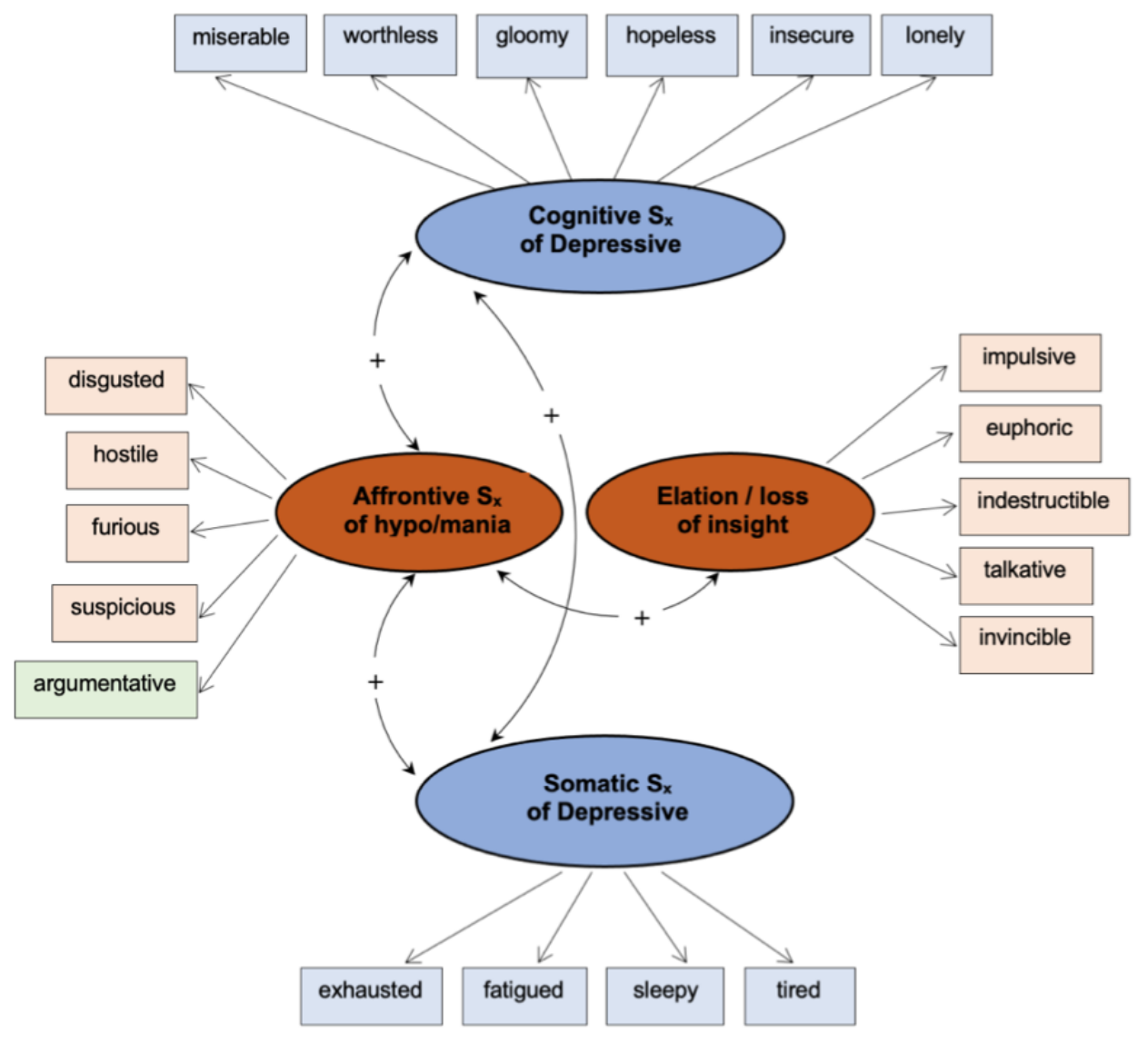




\section{Profiles of Mood States}

Partner affect was assessed using the 15-item version of the profile of mood states (POMS-15), revised for daily diary research [49]. Participants are asked to rate each item on a Likert scale ranging from not at all (1) to a lot (3). POMS-15 items measure 12 negative and 3 positive emotions. This emphasis is based on research indicating that negative affect is (a) more reliably associated with individual functioning within context of acute stress and (b) more likely to be conveyed between partners and influence interpersonal processes than positive affect [48]. Internal consistency for negative POMS items measured over repeated points is high for paramedics and their spouses $(.87<\alpha<.90)$ [50]. In this study, $\alpha=.87$ for negative affect and $\alpha=.74$ for positive affect.

\section{Ecological Momentary Assessment}

At recruitment, BADAS participants and partners specified "windows of general availability" in which they were randomly prompted to complete brief questionnaires on their respective smartphones. Participants were prompted twice daily to complete the $\mathrm{BDS}_{\mathrm{x}}(\mathrm{AM}$ and $\mathrm{PM})$, describe sleep quality (AM), medication adherence (AM), and any important events of the day, the importance of the event, and its impact on mood and perceived control (PM).

Partners completed a single evening questionnaire that included the POMS-15. Positive and negative affect are inversely correlated but distinct aspects of mood associated with distinct brain regions [51]. Positive and negative affect are not endpoints along a single continuum. To our knowledge, this is the first study to examine positive and negative affect as distinct constructs relative to BD symptoms, and the first to measure the effects of affrontive symptoms of hypo/mania on cohabiting carers.

BADAS participants and partners were randomly prompted up to 3 times within 30-minute data collection windows. If they did not respond within the first 20 minutes, the app prompted them again. A third and final prompt was sent 5 minutes thereafter (if they did not respond to the second prompt). Participants could select a distinct or dedicated tone to distinguish study-related prompts from other smartphone sounds [8].

The partner app was yoked to their respective participant's app to collect couple's data within 30 minutes. When the participant responded later than their partner's availability, they were prompted the next morning, before noon. Both the participant and their respective partner could submit voluntary questionnaires any time if they missed a prompted questionnaire or to report a particularly salient event in the moment. Both voluntary and prompted questionnaires were time- and GPS-stamped (ie, longitude and latitude), allowing us to determine if participants and partners were together or apart when their respective questionnaires were submitted.

\section{Participant Remuneration}

BADAS participants were paid \$1 CDN/day (\$0.79 USD) if they complete both the AM and PM questionnaires when prompted. If they missed one AM or PM prompt (not both), they could later submit a voluntary questionnaire. Partners were also paid \$1 CDN/day (\$0.79 USD) on submission of a single $\mathrm{PM}$ questionnaire.

\section{Results}

\section{Viability of Ecological Momentary Assessment with BD couples}

For this pilot study, we identified 312 matched participant and partner app responses from 4 couples over an average of 123 consecutive days (mean 4 months and 3 weeks, range 65-221 days). This sample size is sufficient to detect medium to large effect sizes for correlation coefficients between BD symptomology and partner mood (where $d=.80 ; \alpha=.80$ ) [52].

Although participants are few ( $\mathrm{N}=4$ couples), our ability to collect this volume of in vivo ambulatory data over an extended period supports our first research question (ie, $\mathrm{N}=312$ matched responses). Specifically, data collection using yoked smartphone apps appears to be an effective method for long-term data collection from persons with severe mental illness and their carers (both prompted and ambient data).

\section{Correlational Analyses}

Our ability to collect 312 matched responses from dyads demonstrates the efficacy of ambulatory data collection with BD couples over time (mean 123 days). BADAS participants submitted the $\mathrm{BDS}_{\mathrm{x}}$ before their partners completed the POMS $45 \%$ of the time (139/312; mean 4:50 hrs, SD 5:34 hrs); but most days, partners provided responses before participants (173/312, 55\%; mean 1:52 hrs, SD 3:42 hrs). This sequence was largely random as it began with the participant's PM prompt (ie, within specified PM availability). One or both responses might also have been reported voluntarily that evening, not as prompted questionnaires, which might also change the response order that day (ie, participant then partner vs. partner then participant).

This difference in completion intervals (1:52 hrs vs 4:50 hrs) reflects partners completing the questionnaire the next morning (ie, $\mathrm{BDS}_{\mathrm{x}}$ submitted after partners were no longer available, following their instructions). This was not uncommon, and is consistent with the observation that those with $\mathrm{BD}$ are more likely to be night owls than early birds [53]. In contrast, when partners submitted the POMS first, BADAS participants also completed the $\mathrm{BDS}_{\mathrm{x}}$ that evening.

We next examined correlations between total depression (cognitive and somatic symptoms), total hypo/mania (affrontive symptoms and elation or loss of insight), and partner mood (positive and negative affect). We found that depression had a small but significant association with positive $(\mathrm{r}=-.14 ; P=.02)$ and negative partner affect $(\mathrm{r}=.15 ; P=.01)$. Yet total hypo/mania appears to have no association with positive partner affect $(\mathrm{r}=-.01 ; \quad P=.87)$; instead, negative partner affect was significantly correlated with total hypo/mania $(\mathrm{r}=.26 ; P=.01]$. This coefficient is the largest in this table, suggesting that symptoms of hypo/mania affect partners more than depression. These preliminary findings suggest that symptoms of 
hypo/mania foster sadness (ie, negative affect), not reduce positive affect (Table 1).

Table 1. Correlation coefficients between bipolar disorder symptoms and positive and negative partner mood [N=312]. ${ }^{\mathrm{a}}$

\begin{tabular}{lllll}
\hline & Positive affect & Negative affect & Total depression & Total hypo/mania \\
\hline Positive affect, $r(P$ value $)$ & $-\mathrm{b}$ & $-.45(.01)$ & $-.14(.02)$ & $-.01(.87)$ \\
Negative affect, $\mathrm{r}(P$ value $)$ & $-.45(.01)$ & - & $.15(.01)$ & $.26(.01)$ \\
Total depression, $r(P$ value $)$ & $-.14(.02)$ & $.15(.01)$ & - & $.29(.01)$ \\
Total hypo/mania, $r(P$ value $)$ & $-.01(.87)$ & $.26(.01)$ & $.29(.01)$ & - \\
\hline
\end{tabular}

${ }^{a}$ Statistically significant coefficients are in bold.

${ }^{\mathrm{b}}$ Not applicable.

Consistent with existing research $[47,48]$, depression and hypo/mania are positively correlated $(\mathrm{r}=.29 ; P=.01)$, suggesting that depression and hypo/mania are not inverse clinical states. Often participants reported both types of BD symptoms (eg, mixed features). By contrast, positive and negative partner affect are negatively correlated $(\mathrm{r}=-.45 ; P=.02)$.

\section{Partner Mood and BD Factors}

Above, we noted that the largest coefficient between BADAS participants and partners in Table 1 is between total hypo/mania and negative partner affect $(\mathrm{r}=.26 ; P=.01)$. Yet when we look more closely at BD factors, we see that negative partner affect is associated only with affrontive symptoms of hypo/mania $(\mathrm{r}=.38 ; P=.01)$. Elation or loss of insight appears related to neither positive $(\mathrm{r}=.10 ; P=.09)$ nor negative partner affect (r=.02; $P=.71$; Table 2$)$.

Similarly, we noted that cognitive symptoms of depression were significantly correlated with negative partner affect $(\mathrm{r}=.18$; $P=.01)$; however, negative affect appears unrelated to somatic symptoms $(\mathrm{r}=.03 ; P=.58)$. The inverse is seen with positive partner affect, which is inversely and significantly correlated with somatic symptoms of depression $(\mathrm{r}=-.20 ; P=.01)$ but not cognitive symptoms $(\mathrm{r}=-.05 ; P=.43)$.

Table 2. Correlation coefficients between positive and negative partner mood and bipolar disorder factors $(\mathrm{N}=312){ }^{\mathrm{a}}$

\begin{tabular}{lll}
\hline & Positive affect, $\mathrm{r}(P$ value $)$ & Negative affect, $\mathrm{r}(P$ value $)$ \\
\hline Cognitive $\mathrm{S}_{\mathrm{x}}$ depression & $-.05(.43)$ & $.18(.01)$ \\
Somatic $\mathrm{S}_{\mathrm{x}}$ depression & $-.20(.01)$ & $.03(.58)$ \\
Affrontive $\mathrm{S}_{\mathrm{x}}$ of hypo/mania & $-.10(.07)$ & $.38(.01)$ \\
Elatio, loss of insight & $.10(.09)$ & $.02(.71)$ \\
\hline
\end{tabular}

${ }^{\mathrm{a}}$ Statistically significant coefficients are in bold.

\section{Couples Together and Apart}

As previously noted, symptom and mood questionnaires were time- and GPS-stamped when submitted, allowing us to determine when questionnaires were completed and if couples were together or apart (ie, same GPS coordinates). Cognitive symptoms were significantly associated with negative affect when together and apart, and somatic symptoms were inversely associated with positive affect. Elation or loss of insight was associated with neither positive nor negative mood. What might be described as classic or quintessential mania symptoms (eg, euphoria and impulsivity) appear unrelated to partner mood when couples are together or apart.
By contrast, affrontive symptoms of hypo/mania were significantly correlated with negative affect but only when couples were together $(\mathrm{r}=.41 ; P=.01)$, not when apart $(\mathrm{r}=.22$; $P=.12$ ). This result supports the construct validity of this confrontation-related grouping of symptoms. Consistent with our operational definition, these angry interpersonal symptoms of hypo/mania are experienced most negatively by spouses when couples share the same GPS coordinates. The largest coefficient in these preliminary analyses is between affrontive symptoms and negative partner affect when together $(r=.41$; $P=.01$; Table 3). 
Table 3. Bipolar disorder symptoms and partner mood (positive and negative affect) together and apart. ${ }^{\text {a }}$

\begin{tabular}{llccc}
\hline & \multicolumn{2}{l}{ Positive affect, $\mathrm{r}(P$ value $)$} & \multicolumn{2}{l}{ Negative affect, $\mathrm{r}(P$ value $)$} \\
& Together $^{\mathrm{b}}$ & Apart & Together $^{\mathrm{b}}$ & \multicolumn{1}{c}{ Apart } \\
\hline Cognitive $\mathrm{S}_{\mathrm{x}}$ depression & $.01(.84)$ & $-.22(.13)$ & $.15(.02)$ & $.29(.04)$ \\
Somatic $\mathrm{S}_{\mathrm{X}}$ depression & $-.18(.01)$ & $-.28(.05)$ & $-.02(.72)$ & $.23(.11)$ \\
Affrontive $\mathrm{S}_{\mathrm{x}}$ of hypo/mania & $-.05(.39)$ & $-.19(.19)$ & $.41(.01)$ & $.22(.12)$ \\
Elation or loss of insight & $.10(.13)$ & $.01(.94)$ & $.08(.19)$ & $-.07(.60)$ \\
\hline
\end{tabular}

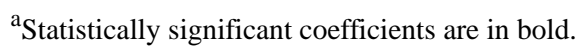

${ }^{\mathrm{b}}$ Participants and partners together when questionnaires submitted (ie, same GPS coordinates).

\section{Discussion}

\section{Principal Findings}

The objectives of this pilot study were to (1) demonstrate the viability of ambulatory data collection with BD couples and (2) identify associations between partner mood and BD symptomology over months of daily data collection. Both objectives were achieved. Moreover, preliminary analyses suggest distinct associations between depression and hypo/mania and positive and negative partner mood. GPS measurement enabled us to determine whether responses were submitted when couples were together or apart (ie, same longitude and latitude). Though recruitment and data collection did not occur as first intended, we largely met or exceeded the standards for ambulatory assessment recommended by Trull and Ebner-Priemer [54].

BADAS participant and partner apps were yoked so that responses from both would be received within 30 minutes, fearing that between-couple effects might dissipate after more than an hour. In other words, time intervals between reporting of BD symptoms and partner mood were longer than intended. However, this makes the number and size of coefficients within couples more noteworthy. For instance, BD symptom levels reported the night before remain correlated with partner mood the next morning, suggesting that the impact of BD symptoms on partners (or partner mood on participants with BD) is not limited to minutes but appears to persist for hours maybe days. Correlation coefficients between BD symptoms and partner mood are similar to coefficients reported between partners without mental illness $[50,55,56]$.

We examined both positive and negative partner affect in relation to BD symptomology in real-time. This proved fortuitous as we found different associations between depression and hypo/mania and positive and negative partner affect. For instance, somatic symptoms of depression are inversely associated with positive affect, whereas cognitive symptoms of depression are significantly correlated with negative affect (not positive affect).

These results are largely consistent with previous research indicating that both depression and hypo/mania affect carer well-being [33]. Our findings have the advantage of measuring both participant symptoms and partner mood each day, close in time, and over several months. Ecological momentary

sampling allowed us to collect responses in real-time, unaffected by recall biases, and in familiar settings (eg, home).

On average, we collected matched symptom-mood responses from couples each day over 3 months and 3 weeks (mean 123 days). By design, completion of app questionnaires required only 3-5 minutes. Brevity of measurement was integral to high participant retention and adherence. This high rate of participation may also be explained by participant remuneration for submission of app questionnaires. Notably, roughly $20 \%$ of BADAS participants opted to give their accumulated monies to a BD charity, suggesting both intrinsic and extrinsic motivation to participate in this study. Some participated to supplement their incomes, whereas others appeared to be motivated to contribute to $\mathrm{BD}$ research.

\section{Limitations and Future Research}

The number, size, and pattern of coefficients we report warrant further study. More elaborate analyses of BD couple dynamics should be undertaken (eg, interactions and time-lagged effects) using contemporary analyses for daily diary analyses (eg, hierarchical linear modeling). Correlational analyses reported herein are preliminary. Most nonsignificant findings would be significant with larger samples; coefficients should be interpreted within ranges (eg, small correlation; .20<r<.35).

The primary limitation of this study is the sample size. We collected information from participants and partners over an extended period, but with only 4 couples; therefore, generalizability of findings is limited. This small sample size limits our ability to (ethically) report full descriptive information. Future study with more couples is needed to identify any gender or cross-national differences.

As noted above, the primary impediment to recruitment for this study was the reticence of BADAS participants to include their spouse or partner. Despite assurances that no information would be shared, the majority of participants asked that we not contact cohabiting spouses or partners. The reasons for this reluctance are not immediately apparent (ie, we did not directly ask). Future couples research should recruit partners first, then cohabiting persons with $\mathrm{BD}$, to determine if this sequence proves more effective.

As recommended by Trull and Ebner-Priemer [54], instruments used in this study were developed and validated for ambulatory assessment. For instance, the $\operatorname{BDS}_{\mathrm{x}}[43,44]$ was specifically developed to briefly measure both symptoms of depression and 
hypo/mania; and though we report good between-person reliability for both the $\mathrm{BDS}_{\mathrm{x}}$ and the POMS-15, ideally, we should report both within-person and between-person reliability.

\section{Implications and Applications}

Results of this study demonstrate the efficacy of EMA in dyadic mental health research. Though participants were few, we collected real-time information each day from couples over 4 months on average. Random data collection using smartphone apps is a viable methodology for longitudinal, dyadic research, including couples where one spouse lives with a chronic mental health condition. Due to the ubiquity of smartphones today, this yoked-app methodology can be applied to a range of mental health research applications. In addition, research is not limited to dyads as extended families and social networks should also be studied in vivo.

EMA data collection functioned effectively, allowing us to collect daily responses from couples when prompted. Yet allowing flexibility such as voluntary or unsolicited responses appears integral to data collection over extended periods. This, however, confounded our objective of collecting responses from both spouses within 30 minutes. Fortunately, results suggest that associations between partner mood and BD symptomology endure over extended periods (eg, the next morning). EMA research opportunities will continue to grow as mobile technology continues to advance.

EMA applications are not limited to research but also include self-care and care management. For example, push notifications (eg, SMS messages) can be generated in real-time, notifying those with BD and possibly their carers (eg, spouses) when responses suggest clinical symptomology. This can foster symptom awareness and help marshal the interpersonal resources needed to cope with and manage $\mathrm{BD}$ mood episodes more effectively.

\section{Acknowledgments}

Support for this study was provided by the Age-Well Network of Centres for Excellence (CRP 2015-WP6.2; NO'R) and the Canadian Institutes of Health Research, Institutes of Aging (RN 134209-259022) awarded to NO'R and A Sixsmith. Portions of this study were presented at the European Congress on Psychology in Moscow, Russia, in July 2019.

\section{Conflicts of Interest}

None declared.

\section{References}

1. Camelo E, Mograbi DC, de Assis da Silva R, Santana CMT, Ferreira do Nascimento RL, de Oliveira e Silva AC, et al. Clinical and Cognitive Correlates of Insight in Bipolar Disorder. Psychiatr Q 2019 Feb 22;90(2):385-394. [doi: 10.1007/s11126-019-09627-2]

2. Glenn T, Monteith S. New Measures of Mental State and Behavior Based on Data Collected From Sensors, Smartphones, and the Internet. Curr Psychiatry Rep 2014 Oct 12;16(12):1-10. [doi: 10.1007/s11920-014-0523-3]

3. Mohr DC, Zhang M, Schueller SM. Personal Sensing: Understanding Mental Health Using Ubiquitous Sensors and Machine Learning. Annu Rev Clin Psychol 2017 May 08;13:23-47. [doi: 10.1146/annurev-clinpsy-032816-044949] [Medline: $\underline{28375728}]$

4. Luxton DD, McCann RA, Bush NE, Mishkind MC, Reger GM. mHealth for mental health: Integrating smartphone technology in behavioral healthcare. Professional Psychology: Research and Practice 2011;42(6):505-512. [doi: 10.1037/a0024485]

5. Faurholt-Jepsen M, Frost M, Vinberg M, Christensen EM, Bardram JE, Kessing LV. Smartphone data as objective measures of bipolar disorder symptoms. Psychiatry Research 2014 Jun;217(1-2):124-127. [doi: 10.1016/j.psychres.2014.03.009] [Medline: 24679993]

6. Faurholt-Jepsen M, Bauer M, Kessing LV. Smartphone-based objective monitoring in bipolar disorder: status and considerations. Int J Bipolar Disord 2018 Jan 23;6(1):6 [FREE Full text] [doi: 10.1186/s40345-017-0110-8] [Medline: 29359252]

7. Harrison PJ, Cipriani A, Harmer CJ, Nobre AC, Saunders K, Goodwin GM, et al. Innovative approaches to bipolar disorder and its treatment. Ann. N.Y. Acad. Sci 2016 Apr 25;1366(1):76-89. [doi: 10.1111/nyas.13048]

8. King D, Sixsmith A, Yaghoubi SH. Developing an ecological momentary sampling tool to measure movement patterns and psychiatric symptom variability. Gerontechnology 2016;14:105. [doi: 10.4017/gt.2016.14.2.006.00]

9. Fraccaro P, Beukenhorst A, Sperrin M. Digital biomarkers from geolocation data in bipolar disorder and schizophrenia. In: Journal of the American Medical Informatics Association. UK: Oxford University Press; Apr 26, 2019:1412-1420.

10. Langer SL, Ghosh N, Todd M, Randall AK, Romano JM, Bricker JB, et al. Usability and Acceptability of a Smartphone App to Assess Partner Communication, Closeness, Mood, and Relationship Satisfaction: Mixed Methods Study. JMIR Form Res 2020 Jul 6;4(7):e14161. [doi: 10.2196/14161]

11. O'Rourke N, King DB. Within-couple analyses of bipolar disorder symptoms and partner mood over time. 2019 Jul 04 Presented at: European Congress on Psychology; 2019, July; Moscow, Russia.

12. Sajatovic M, Chen P, Young R. Rating scales in bipolar disorder. In: Tohen M, Bowden CL, Nierenberg AA, Geddes JR, editors. Clinical Trial Design Challenges in Mood Disorders. Amsterdam: Elsevier; 2015:105-136. 
13. Simon GE, Bauer MS, Ludman EJ, Operskalski BH, Unützer J. Mood symptoms, functional impairment, and disability in people with bipolar disorder: specific effects of mania and depression. J Clin Psychiatry 2007 Aug;68(8):1237-1245. [doi: 10.4088/jcp.v68n0811] [Medline: 17854249 ]

14. DeLongis A, Holtzman S. Coping in Context: The Role of Stress, Social Support, and Personality in Coping. J Personality 2005 Dec;73(6):1633-1656. [doi: 10.1111/j.1467-6494.2005.00361.x]

15. Pfennig A, Littmann E, Bauer M. Neurocognitive Impairment and Dementia in Mood Disorders. JNP 2007 Oct;19(4):373-382. [doi: 10.1176/jnp.2007.19.4.373]

16. Petzold J, Mayer-Pelinski R, Pilhatsch M, Luthe S, Barth T, Bauer M, et al. Short group psychoeducation followed by daily electronic self-monitoring in the long-term treatment of bipolar disorders: a multicenter, rater-blind, randomized controlled trial. Int J Bipolar Disord 2019 Nov 04;7(1):1-9. [doi: 10.1186/s40345-019-0158-8]

17. Bauer M, Wilson T, Neuhaus K, Sasse J, Pfennig A, Lewitzka U, et al. Self-reporting software for bipolar disorder: Validation of ChronoRecord by patients with mania. Psychiatry Research 2008 Jun;159(3):359-366. [doi: 10.1016/j.psychres.2007.04.013]

18. Proudfoot J, Whitton AE, Parker G, Manicavasagar V, Nicholas J, Smith M. Evidence of weekly cyclicity in mood and functional impairment in those with a bipolar disorder. Psychiatry Research 2014 Aug;218(3):290-294. [doi: 10.1016/j.psychres.2014.04.047]

19. Yasui-Furukori N, Nakamura K. Bipolar disorder recurrence prevention using self-monitoring daily mood charts: case reports from a 5 year period. NDT 2017 Mar;Volume 13:733-736. [doi: 10.2147/ndt.s132355]

20. Bauer M, Glenn T, Geddes J, Gitlin M, Grof P, Kessing LV, et al. Smartphones in mental health: a critical review of background issues, current status and future concerns. Int J Bipolar Disord 2020 Jan 10;8(1):1-19. [doi: 10.1186/s40345-019-0164-x]

21. Faurholt-Jepsen M, Busk J, Pórarinsdóttir H, Frost M, Bardram JE, Vinberg M, et al. Objective smartphone data as a potential diagnostic marker of bipolar disorder. Aust N Z J Psychiatry 2018 Nov 02:4867418808900. [doi: 10.1177/0004867418808900] [Medline: 30387368]

22. Faurholt-Jepsen M, Frost M, Busk J, Christensen EM, Bardram JE, Vinberg M, et al. Differences in mood instability in patients with bipolar disorder type I and II: a smartphone-based study. Int J Bipolar Disord 2019 Feb 1;7(1):1-8. [doi: 10.1186/s40345-019-0141-4]

23. Malhi GS, Hamilton A, Morris G, Mannie Z, Das P, Outhred T. The promise of digital mood tracking technologies: are we heading on the right track? Evid Based Mental Health 2017 Aug 30;20(4):102-107. [doi: 10.1136/eb-2017-102757]

24. Dunne L, Perich T, Meade T. The relationship between social support and personal recovery in bipolar disorder. Psychiatric Rehabilitation Journal 2019 Mar;42(1):100-103. [doi: 10.1037/prj0000319]

25. Maurin JT, Boyd CB. Burden of mental illness on the family: A critical review. Archives of Psychiatric Nursing 1990 Apr;4(2):99-107. [doi: 10.1016/0883-9417(90)90016-e]

26. Dols A, Thesing C, Wouters M, Theunissen J, Sonnenberg C, Comijs H, et al. Burden on caregivers of older patients with bipolar disorder. Aging \& Mental Health 2017 Mar 09;22(5):686-691. [doi: 10.1080/13607863.2017.1297360]

27. Steele A, Maruyama N, Galynker I. Psychiatric symptoms in caregivers of patients with bipolar disorder: A review. Journal of Affective Disorders 2010 Feb:10-21. [doi: 10.1016/j.jad.2009.04.020]

28. Zergaw A, Hailemariam D, Alem A. A longitudinal comparative analysis of economic and family caregiver burden due to bipolar disorder. African Journal of Psychiatry. URL: https://hdl.handle.net/10520/EJC72683 [accessed 2021-08-24]

29. Maji K, Sood M, Sagar R, Khandelwal SK. A follow-up study of family burden in patients with bipolar affective disorder. Int J Soc Psychiatry 2011 Mar 18;58(2):217-223. [doi: 10.1177/0020764010390442]

30. Zendjidjian X, Richieri R, Adida M, Limousin S, Gaubert N, Parola N, et al. Quality of life among caregivers of individuals with affective disorders. Journal of Affective Disorders 2012 Feb;136(3):660-665. [doi: 10.1016/j.jad.2011.10.011]

31. Heru AM, Ryan CE. Burden, reward and family functioning of caregivers for relatives with mood disorders: 1-year follow-up. Journal of Affective Disorders 2004 Dec;83(2-3):221-225. [doi: 10.1016/j.jad.2004.04.013]

32. Reinares M, Vieta E, Colom F, Martinezaran A, Torrent C, Comes M, et al. What really matters to bipolar patients' caregivers: Sources of family burden. Journal of Affective Disorders 2006 Aug;94(1-3):157-163. [doi: 10.1016/j.jad.2006.04.022]

33. Chessick C, Perlick D. Suicidal ideation and depressive symptoms among bipolar patients as predictors of the health and well - being of caregivers.Bipolar Disorders 2009;118:876. [doi: 10.1111/j.1399-5618.2009.00765.x]

34. Beentjes T, Goossens P, Poslawsky I. Caregiver burden in bipolar hypomania and mania: A systematic review. Perspectives in Psychiatric Care 2012;484:187. [doi: 10.1111/j.1744-6163.2012.00328.x]

35. Elgie R, Morselli PL. Social functioning in bipolar patients: the perception and perspective of patients, relatives and advocacy organizations ? a review. Bipolar Disorders 2007 Feb;9(1-2):144-157. [doi: 10.1111/j.1399-5618.2007.00339.x]

36. MacQueen G, Young L, Joffe R. A review of psychosocial outcome in patients with bipolar disorder. Acta Psychiatrica Scandinavica 2001;1033:163. [doi: 10.1034/j.1600-0447.2001.00059.x]

37. Pascual-Sánchez A, Jenaro C, Montes-Rodríguez JM. Quality of life in euthymic bipolar patients: A systematic review and meta-analysis. Journal of Affective Disorders 2019 Aug;255:105-115. [doi: 10.1016/j.jad.2019.05.032]

38. Baronet A. Factors associated with caregiver burden in mental illness: a critical review of the research literature. Clinical Psychology Review 1999;197:819. [doi: 10.1016/s0272-7358(98)00076-2] 
39. Perlick D, Rosenheck RR, Clarkin JF, Sirey JA, Raue P, Greenfield S, et al. Burden experienced by care-givers of persons with bipolar affective disorder. Br J Psychiatry 2018 Jan 03;175(1):56-62. [doi: 10.1192/bjp.175.1.56]

40. Goodwin FK, Jamison KR. Manic-depressive illness: Bipolar disorders and recurrent depression, Vol. 2. Oxford University Press 2007.

41. King DB, O'Rourke N, DeLongis A. Social media recruitment and online data collection: A beginner's guide and best practices for accessing low-prevalence and hard-to-reach populations. Canadian Psychology/Psychologie Canadienne 2014;55(4):240-249. [doi: 10.1037/a0038087]

42. Lopez-Castroman J, Courtet P, Baca-Garcia E, Oquendo MA. Identification of suicide risk in bipolar disorder. Bipolar Disord 2014 Oct 24;17(1):22-23. [doi: 10.1111/bdi.12264]

43. O'Rourke N, Sixsmith A, King DB, Yaghoubi-Shahir H, Canham SL. Development and validation of the BDSx: A brief measure of mood and symptom variability for use with adults with bipolar disorder. Int J Bipolar Disord 2016 Mar 1;4(1):1-8. [doi: 10.1186/s40345-016-0048-2]

44. O'Rourke N, Bachner YG, Canham SL, Sixsmith A, Study Team BADAS. Measurement equivalence of the BDSx scale with young and older adults with bipolar disorder. Psychiatry Research 2018 May;263:245-249. [doi: 10.1016/j.psychres.2017.10.024]

45. O'Rourke N, Sixsmith A, Michael T, Bachner YG. Is the 4-factor model of symptomology equivalent across bipolar disorder subtypes? Int J Bipolar Disord 2021 Aug 02;9(24):1-9. [doi: 10.1186/s40345-021-00229-1]

46. O'Rourke N, Sixsmith A, Kirshner G, Osher Y. Perceived cognitive failures and quality of life for older adults with bipolar disorder. Journal of Affective Disorders 2021 May;287:433-440. [doi: 10.1016/j.jad.2021.03.024]

47. Kraun L, O'Rourke N, Osher Y, Bersudsky Y, Belotherkovsky D, Bachner YG. Is the 6-item, self-report HAM-D an effective depression screening measure with bipolar disorder? Perspect Psychiatr Care 2020 Apr 07;56(4):900-904. [doi: 10.1111/ppc.12509]

48. Osher Y, Bersudsky Y, O'Rourke N, Belotherkovsky D, Bachner YG. Clinical validation of the BDSx scale with bipolar disorder outpatients. Archives of Psychiatric Nursing 2020 Feb;34(1):49-52. [doi: 10.1016/j.apnu.2019.11.002]

49. Cranford JA, Shrout PE, Iida M, Rafaeli E, Yip T, Bolger N. A Procedure for Evaluating Sensitivity to Within-Person Change: Can Mood Measures in Diary Studies Detect Change Reliably? Pers Soc Psychol Bull 2016 Jul 02;32(7):917-929. [doi: 10.1177/0146167206287721]

50. King BD. Daily dynamics of stress in Canadian paramedics and their spouses. University of British Columbia Open Collections 2013 Oct:1-152 [FREE Full text]

51. Lindquist KA, Satpute AB, Wager TD, Weber J, Barrett LF. The Brain Basis of Positive and Negative Affect: Evidence from a Meta-Analysis of the Human Neuroimaging Literature. Cereb. Cortex 2015 Jan 28;26(5):1910-1922. [doi: 10.1093/cercor/bhv001]

52. Cohen J. A power primer. In: Kazdin AE, editor. Methodological issues \& strategies in clinical research: American Psychological Association; 2013:427-436.

53. Melo MC, Abreu RL, Linhares Neto VB, de Bruin PF, de Bruin VM. Chronotype and circadian rhythm in bipolar disorder: A systematic review. Sleep Medicine Reviews 2017 Aug;34:46-58. [doi: 10.1016/j.smrv.2016.06.007]

54. Trull TJ, Ebner-Priemer UW. Ambulatory assessment in psychopathology research: A review of recommended reporting guidelines and current practices. Journal of Abnormal Psychology 2020 Jan;129(1):56-63. [doi: 10.1037/abn0000473]

55. McDaniel BT, Teti DM, Feinberg ME. Predicting coparenting quality in daily life in mothers and fathers. Journal of Family Psychology 2018 Oct;32(7):904-914. [doi: 10.1037/fam0000443]

56. McDaniel BT, Drouin M. Daily technology interruptions and emotional and relational well-being. Computers in Human Behavior 2019 Oct;99:1-8. [doi: 10.1016/j.chb.2019.04.027]

\section{Abbreviations}

BD: bipolar disorder

BADAS: bipolar affective disorders and older adults study

BDSx: bipolar disorder symptom scale

EMA: ecological momentary assessment

POMS-15: profiles of mood states 
Edited by G Eysenbach; submitted 16.05.21; peer-reviewed by A Shrira; comments to author 14.07.21; revised version received 21.07.21; accepted 01.08.21; published 02.09.21

Please cite as:

Yerushalmi M, Sixsmith A, Pollock Star A, King DB, O'Rourke N

Ecological Momentary Assessment of Bipolar Disorder Symptoms and Partner Affect: Longitudinal Pilot Study JMIR Form Res 2021;5(9):e30472

URL: https://formative.jmir.org/2021/9/e30472

doi: $10.2196 / 30472$

PMID:

CMor Yerushalmi, Andrew Sixsmith, Ariel Pollock Star, David B King, Norm O'Rourke. Originally published in JMIR Formative Research (https://formative.jmir.org), 02.09.2021. This is an open-access article distributed under the terms of the Creative Commons Attribution License (https://creativecommons.org/licenses/by/4.0/), which permits unrestricted use, distribution, and reproduction in any medium, provided the original work, first published in JMIR Formative Research, is properly cited. The complete bibliographic information, a link to the original publication on https://formative.jmir.org, as well as this copyright and license information must be included. 